\title{
Overexpression of a Novel Component Induces HAK5 and Enhances Growth in Arabidopsis
}

\author{
Eri Adams, ${ }^{1}$ Celine Diaz, ${ }^{1,2}$ Minami Matsui, ${ }^{1}$ and Ryoung Shin ${ }^{1}$ \\ ${ }^{1}$ RIKEN Center for Sustainable Resource Science, 1-7-22 Suehirocho, Tsurumi-ku, Yokohama, Kanagawa 230-0045, Japan \\ ${ }^{2}$ Center for Research in Agricultural Genomics (CRAG), Universitat Autònoma de Barcelona, Cerdanyola del Vallès, \\ 08193 Barcelona, Spain
}

Correspondence should be addressed to Ryoung Shin; ryoung.shin@riken.jp

Received 13 November 2013; Accepted 10 December 2013; Published 21 January 2014

Academic Editors: C. Chang, I. Paponov, and C. Xu

Copyright (c) 2014 Eri Adams et al. This is an open access article distributed under the Creative Commons Attribution License, which permits unrestricted use, distribution, and reproduction in any medium, provided the original work is properly cited.

\begin{abstract}
Plants have developed mechanisms to adapt to the potassium deficient conditions over the years. In Arabidopsis thaliana, expression of a potassium transporter HAK5 is induced in low potassium conditions as an adaptive response to nutrient deficiency. In order to understand the mechanism in which HAK5 is regulated, the full-length cDNA overexpressor gene hunting system was employed as a screening method. Of 40 genes recovered, At $4 \mathrm{~g} 18280$ was found to be dramatically induced in response to potassium-deficiency and salt stress. Plants overexpressing this gene showed higher HAK5 expression and enhanced growth. These plants were also less sensitive to potassium-deficiency in terms of primary root growth. Taken together, these data suggest that this novel component, At4g18280, contributes to regulation of HAK5 and, consequently, tolerance to potassium-deficiency in plants.
\end{abstract}

\section{Introduction}

Potassium $\left(\mathrm{K}^{+}\right)$is an essential plant macronutrient and the most abundant inorganic cation in higher plants. $\mathrm{K}^{+}$ functions as a major osmoticum which regulates turgor pressure and membrane potentials to drive plant growth. $\mathrm{K}^{+}$is also important for a variety of vital physiological processes in plants such as enzyme activities, phloem transport, photosynthesis, and stress response. Therefore, $\mathrm{K}^{+}$deficiency is observed as growth arrest due to a variety of physiological retardations including reduced photosynthesis and impaired phloem transport of sucrose, reviewed in [1-3]. One commonly observed adaptation mechanism providing plants with better access to limited nutrients is alteration of the root architecture such as root hair formation, primary root growth, and lateral root formation [4].

In order to respond to the wide range of $\mathrm{K}^{+}$concentrations in the soil, plants have also developed sophisticated $\mathrm{K}^{+}$uptake systems. In Arabidopsis, the major $\mathrm{K}^{+}$channel functioning in the roots under the $\mathrm{K}^{+}$-sufficient conditions is assumed to be $\mathrm{K}^{+}$TRANSPORTER1 (AKT1) [5]. In response to $\mathrm{K}^{+}$-deficiency, expression of high-affinity $\mathrm{K}^{+}$transporters, members of the $\mathrm{K}^{+}$uptake permease (KUP) family, is induced such as HIGH-AFFINITY $\mathrm{K}^{+}$TRANSPORTER5 (HAK5) and KUP3 $[6,7]$ such that the ability to absorb $\mathrm{K}^{+}$is increased under the limited conditions. Of these transporters, HAK5 is probably the most well-studied high-affinity $\mathrm{K}^{+}$transporter in Arabidopsis. Upon $\mathrm{K}^{+}$-deficiency, ethylene production is rapidly induced followed by reactive oxygen species (ROS) accumulation to upregulate expression of HAK5 $[8,9]$. Recently, it has been reported that expression of HAK5 is also induced in response to cesium, which belongs to the same alkali metal group as $\mathrm{K}^{+}$and competes with $\mathrm{K}^{+}$in terms of uptake in plants, although it is not known whether HAK5 induction is due to $\mathrm{K}^{+}$-deficiency caused by cesium [10]. Several transcription factors are suggested to regulate HAK5 expression including RAP2.11, DDF2, JLO, TF_IIA, and bHLH121 [11, 12]. It is important to understand detailed mechanisms by which plants maintain their survival under $\mathrm{K}^{+}$-deficiency, especially from an agricultural point of view. However, molecular mechanisms of plant response to $\mathrm{K}^{+}$deficiency are not well known.

To investigate the upstream factors which regulate the expression of HAK5, the FOX (full-length cDNA overexpressor) gene hunting system in the background of Arabidopsis plants carrying the HAK5 promoter fused to the luciferase 
reporter construct (HAK5pro::LUC) was created. The Arabidopsis FOX collection in Agrobacterium tumefaciens contains around 10,000 independent normalised full-length cDNA from Arabidopsis under the control of CaMV 35S promoter [13]. The FOX hunting system is a gain-of-function system and is a powerful tool to screen the responsible genes involved in a phenotype of interest. Using this system, we found a series of genes which induce expression of HAK5 and some of these are induced themselves in response to $\mathrm{K}^{+}$deficiency. Of those, a gene At4g18280 was strongly induced by $\mathrm{K}^{+}$-deficiency as well as salt stress. Plants overexpressing this gene showed better growth and resistance to $\mathrm{K}^{+}$deficiency but their $\mathrm{K}^{+}$and sodium $\left(\mathrm{Na}^{+}\right)$concentrations were not altered. Taken together, we propose that this protein of unknown function At4g18280, in coordination with HAK5, may regulate efficient use and allocation of nutrients.

\section{Materials and Methods}

2.1. Plant Materials, Luciferase Imaging, and Growth Conditions. The Arabidopsis thaliana accession Col-0 was used as a wild type. Agrobacterium library containing Arabidopsis FOX [13] was transformed into 128 plants each of three independent HAK5promoter::LUC lines, HAK5pro::LUC-2, HAK5pro::LUC-8 and HAK5pro::LUC-12 [9, 12]. The T1 plants were selected for their resistance to hygromycin. A total of 877 plants were recovered, transferred onto control plates without antibiotics, and grown for 7 days before imaging.

Plants were sprayed with luciferin (Duchefa Biochemie, Haarlem, The Netherlands) and kept in the dark for a few minutes prior to imaging. NightSHADE LB 985 (Berthold, Bad Wildbad, Germany) was used to image luciferase chemiluminescence. Those plants with higher luciferase activities compared to the background lines were selected for further analysis. The second, third, and fourth screenings were performed in subsequent generations to narrow down the candidates.

Seeds were sown on media containing $1.25 \mathrm{mM} \mathrm{KNO}_{3}$, $1.5 \mathrm{mM} \mathrm{Ca}\left(\mathrm{NO}_{3}\right)_{2}, \quad 0.5 \mathrm{mM} \mathrm{KH}_{2} \mathrm{PO}_{4}, \quad 0.75 \mathrm{mM} \mathrm{MgSO}_{4}$, $50 \mu \mathrm{M} \mathrm{H}_{3} \mathrm{BO}_{3}, 10 \mu \mathrm{M} \mathrm{MnCl}, 2 \mu \mathrm{M} \mathrm{ZnSO}, 1.5 \mu \mathrm{M} \mathrm{CuSO}_{4}$, $0.075 \mu \mathrm{M} \mathrm{NH} \mathrm{No}_{7} \mathrm{O}_{24}$, and $74 \mu \mathrm{M}$ Fe-EDTA, pH 5.8, with $\mathrm{Ca}(\mathrm{OH})_{2}, 1 \%(\mathrm{w} / \mathrm{v})$ sucrose, and $0.5 \%(\mathrm{w} / \mathrm{v})$ phyto agar (Duchefa Biochemie) for screening. For physiological and qRT-PCR assays, media containing $1.75 \mathrm{mM} \mathrm{KCl}$, $2 \mathrm{mM} \mathrm{Ca}\left(\mathrm{NO}_{3}\right)_{2}, \quad 0.5 \mathrm{mM}$ phosphoric acid, $0.75 \mathrm{mM}$ $\mathrm{MgSO}_{4}, 50 \mu \mathrm{M} \mathrm{H}_{3} \mathrm{BO}_{3}, 10 \mu \mathrm{M} \mathrm{MnCl}, 2 \mu \mathrm{M} \mathrm{ZnSO}, 1.5 \mu \mathrm{M}$ $\mathrm{CuSO}_{4}, 0.075 \mu \mathrm{M} \mathrm{NH} \mathrm{Mo}_{7} \mathrm{O}_{24}$, and $74 \mu \mathrm{M}$ Fe-EDTA, $\mathrm{pH}$ 5.8, with $\mathrm{Ca}(\mathrm{OH})_{2}, 1 \%$ sucrose, and $1 \%$ SeaKem agarose (Lonza, Basel, Switzerland) were used as control. For non-potassium $(-\mathrm{K})$ media, $\mathrm{KCl}$ was excluded. For nonphosphorus ( $-\mathrm{P})$ media, phosphoric acid was excluded. For non-nitrogen $(-\mathrm{N})$ media, $\mathrm{Ca}\left(\mathrm{NO}_{3}\right)_{2}$ was replaced with $\mathrm{CaCl}_{2}$. For $\mathrm{NaCl}$ media, $100 \mathrm{mM} \mathrm{NaCl}$ was added. After stratification for 3 to 4 days at $4^{\circ} \mathrm{C}$, plants were placed vertically in a growth cabinet at $22^{\circ} \mathrm{C}$ in a 16-hour light/8-hour dark photocycle with a light intensity of $70-90 \mu \mathrm{mol} / \mathrm{m}^{2} / \mathrm{s}$.
2.2. Confirmation of Inserted cDNA and Sequencing. The selected seedlings were transferred into soil and a few rosette leaves were flash-frozen in liquid $\mathrm{N}_{2}$. The samples were ground using a mixer mill and genomic DNA was extracted. A single insertion of a cDNA fragment was confirmed by PCR using a primer set: F2 $5^{\prime}$-CATTTATTCGGAGAGGTACGTAT and R2 $5^{\prime}$-GGATTCAATCTTAAGAAACTTTATTGCCAA [14]. The PCR products were purified using a Wizard SV Gel and PCR Clean-Up System (Promega, Wisconsin, USA) and sequenced using a F6 primer: $5^{\prime}$-CCCCCCCCCCCCD (A or G or T).

2.3. $q R T-P C R$ Analysis. For HAK5 and FOX gene expression in Col-0, seedlings were grown on control media for 3 days, transferred onto $-\mathrm{K},-\mathrm{N},-\mathrm{P}$, or $100 \mathrm{mM} \mathrm{NaCl}$ media, and grown for 7 days. The samples were flash-frozen in liquid $\mathrm{N}_{2}$ and ground using a mixer mill. Total RNA was extracted, treated with DNaseI (Invitrogen, California, USA), and synthesised into cDNA using SuperScript III (Invitrogen). Quantitative real-time reverse transcriptionPCR (qRT-PCR) was performed using THUNDERBIRD SYBR qPCR mix (TOYOBO, Osaka, Japan) and a Mx3000P qPCR system (Agilent Technologies, California, USA). The amplification conditions were $95^{\circ} \mathrm{C}$ for 15 seconds and $60^{\circ} \mathrm{C}$ for 30 seconds. The cycle was repeated 40 times, preceded by $95^{\circ} \mathrm{C}$ for 1 minute and followed by a dissociation programme to create melting curves. Three biological replicates with three technical replicates for each treatment were run. The $\beta$-tubulin gene (TUB2) was used as a reference gene. The primers used are summarised in Supplemental Table 1 as shown in supplementary material available online at http://dx.doi.org/10.1155/2014/490252. Primer sequences of HAK5 and TUB2 have been previously published [15]. Oneway ANOVA with Dunnett's multiple comparison posttest $(P<0.05)$ or $t$-test with Welch's correction $(P<0.05)$ was performed using Prism (GraphPad Software, California, USA) to determine the statistical significance.

2.4. Root Growth Assay. FOX lines and Col-0 were grown on control media for 3 days, transferred onto media with or without $\mathrm{K}^{+}$and grown for 11 days. Plates were scanned and primary root lengths were measured using ImageJ (http://rsbweb.nih.gov/ij/). Roots and shoots were separated and weighted on a precision balance. One-way ANOVA with Bonferroni's multiple comparison posttest was performed using Prism to determine the statistical significance.

2.5. Potassium and Sodium Concentration Analysis. FOX lines and Col-0 were grown on control media for 3 days, transferred onto media with or without $\mathrm{K}^{+}$and grown for 11 days. Seedlings were washed in MilliQ water, dried on a piece of paper towel, placed in a paper envelope, and dried in an oven at $65^{\circ} \mathrm{C}$ for 3 to 4 days. Approximately $2 \mathrm{mg}$ of dried samples were extracted in $1 \mathrm{~mL}$ of $60 \%(\mathrm{v} / \mathrm{v}) \mathrm{HNO}_{3}$ at $125^{\circ} \mathrm{C}$ for 1 hour followed by $1 \mathrm{~mL}$ of $30 \%$ (v/v) $\mathrm{H}_{2} \mathrm{O}_{2}$ and diluted with MilliQ water to get total volume of $10 \mathrm{~mL}$. The samples were further diluted 10 or 100 times with $6 \%$ $(\mathrm{v} / \mathrm{v}) \mathrm{HNO}_{3} \cdot \mathrm{K}^{+}$and $\mathrm{Na}^{+}$concentrations were measured 
Col-0

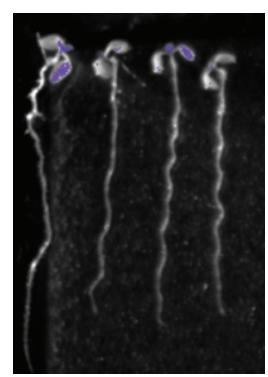

HAK5-12

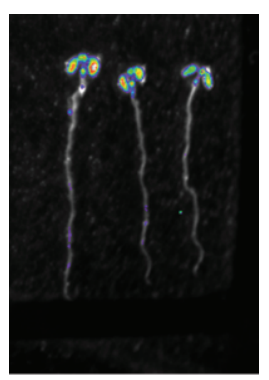

FOX1

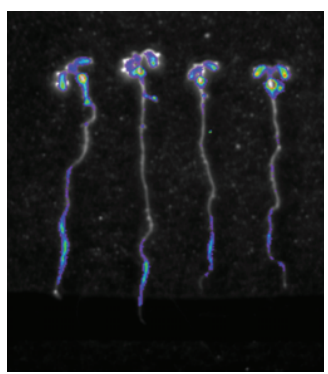

HAK5-8

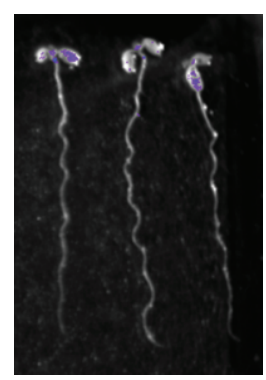

FOX2

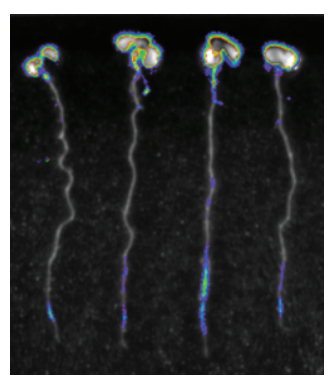

FIGURE 1: Chemiluminescence imaging of Col-0 and two FOX lines with their parental lines (HAK5pro::LUC-12 for FOX1, HAK5pro::LUC8 for FOX2) grown for 7 days under the control condition. Pseudocolour represents the intensity of chemiluminescence. FOX1 expresses At4g18280; FOX2 expresses At2g36370.

on a flame atomic absorption spectrometer AAnalyst 200 (PerkinElmer). Concentrations were calculated against each standard curve and one-way ANOVA with Bonferroni's multiple comparison posttest $(P<0.05)$ was performed using Prism to determine the statistical significance.

\section{Results}

3.1. Screening and Selection of Candidate Genes which Induce HAK5 Expression. The high-affinity $\mathrm{K}^{+}$transporter, HAK5, is a crucial component for plant growth and survival especially under the $\mathrm{K}^{+}$-deficient conditions. Expression of HAK5 is known to be rapidly induced in response to $\mathrm{K}^{+}$-deficiency but promptly reverts to basal levels upon resupply of $\mathrm{K}^{+}$however the detailed mechanism of this exquisite regulation is not well known. In order to seek out the components involved in regulation of HAK5 expression, Arabidopsis plants carrying the HAK5pro::LUC reporter constructs were transformed with Agrobacterium library containing Arabidopsis FOX [13]. The T1 population was segregated on selection media containing hygromycin. The resistant plants were transferred onto control media which contained sufficient amounts of $\mathrm{K}^{+}$. In this condition, expression of HAK5 is not induced; therefore, luciferase activity is minimal for the parental HAK5pro::LUC lines. Out of 877 transformants, upon multiple screenings of subsequent generations, 47 candidate lines were selected for enhanced luciferase activity compared to their parental lines (Figure 1). Genomic DNA for each line was extracted, PCR was performed to confirm the insertion of FOX genes and purified PCR fragments were sequenced. A total of 40 genes were recovered (Table 1), of which 9 genes were recovered from two independent plant lines and two plant lines hosted two FOX genes. Endogenous HAK5 expression was also determined to be induced in the selected FOX lines (Table 1).

Since the candidate genes were expected to be involved in induction of HAK5 expression which is known to be induced under $\mathrm{K}^{+}$-deficiency, we tested whether expression of these genes was also differentially regulated under $\mathrm{K}^{+}$-deficiency. Of 11 candidate genes selected, 5 genes were found to be induced in response to $\mathrm{K}^{+}$-deficiency in the roots and 3 genes in the shoots also (Table 2). These results are consistent with the predominant role of HAK5 in the roots.
3.2. Involvement of FOX Genes in Other Nutrient Deficiency and Salt Stress. Five FOX genes that were induced in response to $\mathrm{K}^{+}$-deficiency in the roots, At4g18280, At5g47790, At5g22360, At5g55310, and At2g36370 (Table 2), were also analysed under nitrogen-deficiency, phosphorusdeficiency, and salt stress in order to investigate whether they are general nutrient stress-response factors. Moderate increases $(P<0.05)$ of At5g47790 in nitrogendeficiency, At5g22360 in phosphorus-deficiency (Supplemental Figure 1) and a dramatic increase $(P<0.01)$ of At4g18280 under salt stress (Figure 2(a)) were observed. Some $\mathrm{K}^{+}$transporter genes including HAK5 are known to be induced in response to salt stress $[12,16,17]$, possibly causing similar effects as $\mathrm{K}^{+}$-deficiency to plants. Our data might indicate that At4g18280 could regulate expression of HAK5 not only under $\mathrm{K}^{+}$-deficiency but also under salt stress.

3.3. Phenotype of FOX Lines in $\mathrm{K}^{+}$-Deficiency. Five FOX lines expressing the genes that are induced in response to $\mathrm{K}^{+}$deficiency (Table 2) were investigated for their phenotype. The FOX lines expressing At5g47790, At5g22360, At5g47790, and At2g36370 (FOX2) did not show altered growth in terms of primary root length compared to wild type (Col0 ) under $\mathrm{K}^{+}$-deficiency. However, the FOX line expressing At4g18280 (FOX1) showed enhanced growth in the $\mathrm{K}^{+}$deficient condition (Figures 2(b) and 2(c)). FOX1 contains full-length At4g18280 and its expression levels are 47.5 times more in average than one in its parental line, HAK5pro::LUC12 ( $\log _{2}$ fold change 5.57$)$. FOX1 also contains a second FOX gene At5g59160, tandem with At4g18280 but expression of this gene was not enhanced $\left(\log _{2}\right.$ fold change -0.01$)$.

Further analysis of FOX1 revealed that its lateral root number, lateral root density, and both root and shoot weight were increased in the control condition (Figure 3), suggesting that induction of At4g18280 expression renders enhanced growth to plants.

3.4. $\mathrm{K}^{+}$and $\mathrm{Na}^{+}$Accumulation in FOX1. According to our data, a protein annotated as a glycine-rich cell wall protein (At4g18280) seems to be involved in regulation of HAK5 expression. Since HAK5 is a $\mathrm{K}^{+}$transporter which absorbs exogenous $\mathrm{K}^{+}$into the root system, predominantly working 
TABLE 1: List of the genes that were identified in the HAK5pro::LUC reporter lines transformed with FOX library for increased luciferase activity. Number of the lines that were recovered for each gene is given as a hit number, if multiple. Endogenous HAK5 expression levels in the roots for selected lines are also given as $\log _{2}$ fold change compared to their parental HAK5pro::LUC lines under the control condition.

\begin{tabular}{|c|c|c|c|}
\hline AGI & Gene description & Hit & HAK5 \\
\hline Atlg17620 & Late embryogenesis abundant (LEA) hydroxyproline-rich glycoprotein family & 2 & \\
\hline Atlg23310 & $\begin{array}{l}\text { ALANINE-2-OXOGLUTARATE AMINOTRANSFERASE } 1 \text { (AOAT1), } \\
\text { GLUTAMATE:GLYOXYLATE AMINOTRANSFERASE } 1 \text { (GGAT1) }\end{array}$ & 2 & \\
\hline Atlg29050 & Trichome birefringence-like 38 (TBL38) & & \\
\hline Atlg34000 & One-helix protein 2 (OHP2) & & \\
\hline Atlg48630 & Receptor for activated C kinase 1B (RACK1B) & & 7.845 \\
\hline Atlg51590 & Alpha-mannosidase 1 (MNS1) & & \\
\hline Atlg56580 & Smaller with variable branches (SVB) & & \\
\hline Atlg62380 & ACC oxidase $2(\mathrm{ACO} 2)$ & 2 & \\
\hline Atlg69530 & Expansin $1(\mathrm{EXP} 1)$ & & \\
\hline At2g01970 & Endomembrane protein 70 protein family & 2 & \\
\hline At2g21660 & $\begin{array}{l}\text { Cold, circadian rhythm, and RNA binding } 2 \text { (CCR2), glycine-rich RNA-binding } \\
\text { protein } 7 \text { (GRP7) }\end{array}$ & 2 & \\
\hline At2g34830 & $\begin{array}{l}\text { WRKY DNA-binding protein } 35 \text { (WRKY35), maternal effect EMBRYO ARREST } 24 \\
\text { (MEE24) }\end{array}$ & & \\
\hline At2g36370 & Ubiquitin-protein ligase & & 0.906 \\
\hline At2g36895 & Unknown protein & & \\
\hline At3g07430 & Embryo defective 1990 (EMB1990) & & \\
\hline At3g53730 & Histone superfamily protein & & \\
\hline At4g03190 & Auxin signaling f-box protein1 (AFB1), GRR1-like protein 1 (GRH1) & & \\
\hline At4g03960 & Plant, and fungi atypical dual-specificity phosphatase 4 (PFA-DSP4) & & \\
\hline At4g13195 & Clavata3/ESR-related 44, CLE44 & & \\
\hline At4g18280 & Glycine-rich cell wall protein related & & 1.581 \\
\hline At4g22190 & unknown (EAR motif) & & \\
\hline At4g25240 & GPI-anchored SKU5-like protein (SKS1) & & \\
\hline At4g28860 & Casein kinase-like 4 (ckl4); & & \\
\hline At5g01820 & SnRK3.5, CIPK14 & & \\
\hline At5g03040 & IQ-DOMAIN 2 (IQD2) & & 6.856 \\
\hline At5g09760 & pectinesterase family protein & & \\
\hline At5g14740 & Carbonic anhydrase 2 (CA2) & & \\
\hline At5g15410 & $\begin{array}{l}\text { CYCLIC NUCLEOTIDE GATED CHANNEL2 (CNGC2), defense no death } 1 \\
\text { (DND1) }\end{array}$ & & \\
\hline At5g22360 & Vesicle-associated membrane protein 714 (VAMP714) & & 0.902 \\
\hline At5g44160 & Nutcracker (NUC) & & \\
\hline At5g44750 & Homologous to Y-family DNA polymerase (REV1) & 2 & \\
\hline At5g47790 & SMAD/FHA domain-containing protein & & \\
\hline At5g52880 & F-Box family protein & 2 & \\
\hline At5g54585 & Unknown protein & & \\
\hline At5g55310 & Topoisomerase 1 (TOP1) & 2 & 6.104 \\
\hline At5g57360 & FKF1-like protein 2 (FKL2) & & \\
\hline At5g59160 & Type one serine/threonine protein phosphatase 2 (TOPP2) & & \\
\hline At5g59320 & Lipid transfer protein 3 (LTP3) & 2 & \\
\hline At5g59500 & Unknown protein & & \\
\hline At5g61250 & Glucuronidase 1 (GUS1) & & \\
\hline
\end{tabular}


TABLE 2: List of the genes that were analysed for their response to potassium deficiency ( $-\mathrm{K})$. Expression levels of each candidate gene under $-\mathrm{K}$ in roots and shoots of wild type plants (Col-0) are given as $\log _{2}$ fold change compared to the ones under the control condition. Statistically significant difference is marked in bold. b.d. indicates below detection.

\begin{tabular}{llcc}
\hline AGI & Description & Root & Shoot \\
\hline At5g47790 & SMAD/FHA domain-containing protein & $\mathbf{1 . 1 4}$ & -0.13 \\
At5g03040 & IQ-domain 2 (iqd2) & - \\
At5g55310 & Topoisomerase 1 (TOP1) & $\mathbf{0 . 6 4}$ & b.d. \\
At5g22360 & Vesicle-associated membrane protein 714 (VAMP714) & $\mathbf{0 . 4 4}$ & $\mathbf{- 0 . 8 6}$ \\
At4g18280 & glycine-rich cell wall protein related & $\mathbf{4 . 1 4}$ & $\mathbf{5 . 1 9}$ \\
At2g21660 & cold, circadian rhythm, and RNA binding 2 (CCR2), glycine-rich & -0.21 & $\mathbf{1 . 1 7}$ \\
At2g36370 & RNA-binding protein 7 (GRP7) & $\mathbf{1 . 5 3}$ & $\mathbf{1 . 0 9}$ \\
At4g03960 & Ubiquitin-protein ligase & b.d. \\
At5g44160 & plant and fungi atypical dual-specificity phosphatase 4 (PFA-DSP4) & b.d. \\
At5g01820 & Nutcracker (NUC) & 0.26 \\
At1g48630 & SnRK3.5, CIPK14 & - & 0.06
\end{tabular}

under the $\mathrm{K}^{+}$-deficient conditions, the role of At4g18280 in this process was investigated. FOX1 expressing At4g18280 was grown in $\mathrm{K}^{+}$-sufficient and -deficient conditions and $\mathrm{K}^{+}$ concentrations in the seedlings were determined. In both sufficient and deficient conditions, $\mathrm{K}^{+}$levels were comparable to those in Col-0 (Figure 4(a)), indicating that, although At4g18280 is involved in induction of HAK5 expression, it does not contribute to $\mathrm{K}^{+}$accumulation.

Accumulation of $\mathrm{Na}^{+}$was also determined in FOX1 under $\mathrm{K}^{+}$-deficiency and salt stress. $\mathrm{Na}^{+}$concentrations in FOX1 were also comparable to those in Col-0 under the conditions tested (Figure 4(b)), suggesting that At4g18280 alone is perhaps not sufficient for activation of HAK5 for $\mathrm{K}^{+}$ or $\mathrm{Na}^{+}$uptake.

\section{Discussion}

It is important for plants to efficiently absorb a macronutrient $\mathrm{K}^{+}$especially when $\mathrm{K}^{+}$is not readily available. Upon $\mathrm{K}^{+}$deficiency, Arabidopsis quickly induces expression of a highaffinity $\mathrm{K}^{+}$transporter HAK5 and increases the efficiency of $\mathrm{K}^{+}$uptake. In order to understand the detailed regulatory mechanism of HAK5 expression and components involved in this process, plants carrying the HAK5 promoter fused to a luciferase reporter gene, HAK5pro::LUC, were transformed with the FOX library and analysed. After multiple screenings, 47 plants out of 877 were selected for increased luciferase activities under the non-inducing condition. Sequencing of the FOX genes expressed in each FOX plant revealed 40 genes which might be responsible for inducing HAK5 expression. Randomly selected plant lines were tested for endogenous expression of HAK5 to confirm the integrity of the system. Nine of the genes recovered were represented in two independent FOX lines, suggesting importance of those genes and validity of the screening. These include At1g23310, ALANINE-2-OXOGLUTARATE AMINOTRANSFERASE1 (AOAT1)/GLUTAMATE:GLYOXYLATE AMINOTRANSFERASE1 (GGAT1), Atlg62380, ACC OXIDASE2 (ACO2), and At5g44750, DNA polymerase REV1. It has been reported that ethylene production in response to $\mathrm{K}^{+}$deficiency is required for ROS accumulation and consequent HAK5 expression [9]. AOAT1/GGAT1 is suggested in 1aminocyclopropane-1-carboxylate (ACC) biosynthesis, the first step of ethylene biosynthesis, according to the GO term and $\mathrm{ACO} 2$ is an enzyme which converts ACC into ethylene. Another member of the ACO family, ACO1 was previously shown to be induced in response to $\mathrm{K}^{+}$-deficiency [8]. Moreover, REV1 is suggested to be involved in biosynthesis of hydrogen peroxide, a form of ROS, according to the GO term. Our results reinforce previous findings that overexpression of ethylene or ROS biosynthesis genes can mimic $\mathrm{K}^{+}$-deficiency response in terms of HAK5 induction. Other genes are represented in one plant line such as At5g15410, CYCLIC NUCLEOTIDE GATED CHANNEL2 (CNGC2) and At4g03190, AUXIN SIGNALING F-BOX PROTEIN1 (AFB1). CNGC2 was reported to function as a monovalent cation channel and conduct $\mathrm{K}^{+}$but not $\mathrm{Na}^{+}$[18], and therefore it is possible that CNGC2 and HAK5 are coregulated in response to $\mathrm{K}^{+}$-deficiency. The relationship between auxin and $\mathrm{K}^{+}$-deficiency was also previously reported [19]. The gene list also includes a few genes related to protein degradation such as F-box proteins and ubiquitin-protein ligase, suggesting involvement of this process in $\mathrm{K}^{+}$-deficiency response.

In order to find novel components that are coregulated with $H A K 5$, transcript levels of 11 selected genes in response to $\mathrm{K}^{+}$-deficiency was tested in roots and shoots. Of those, five genes in roots and three genes in shoots showed statistically significant induction in reference to the $\mathrm{K}^{+}$sufficient condition. Induction of a gene encoding a protein annotated as glycine-rich cell wall protein (At4g18280) and a gene encoding an ubiquitin-protein ligase (At2g36370) were particularly high in both tissues. Previous microarray results also showed increased transcript levels of At4g18280 in shoots of $\mathrm{K}^{+}$-starved Arabidopsis plants [20]. Upon physiological studies of the FOX lines, only FOX1 with At4g18280 was 


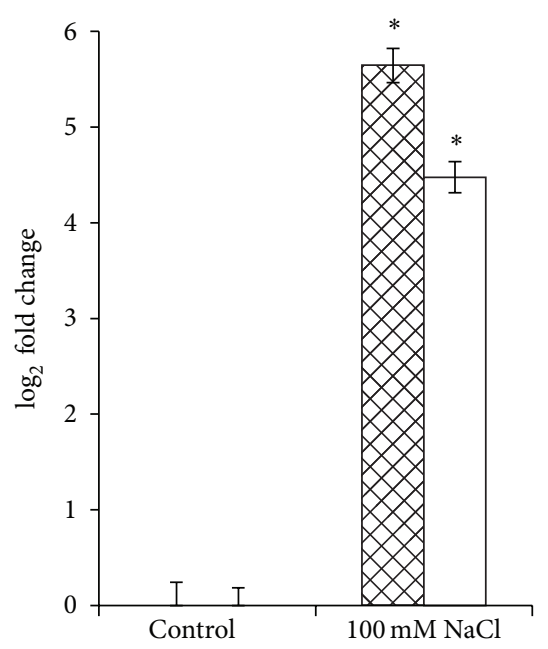

(a)

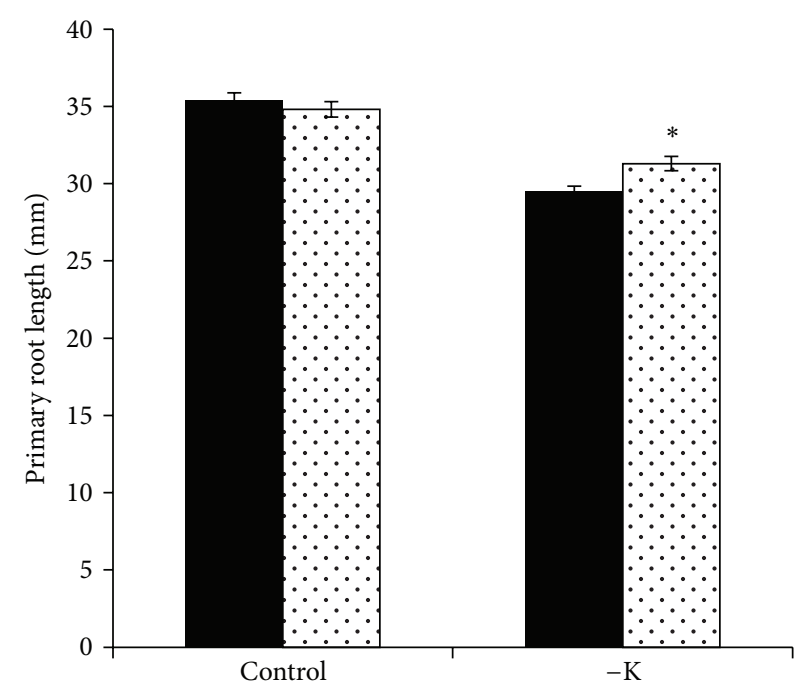

(b)
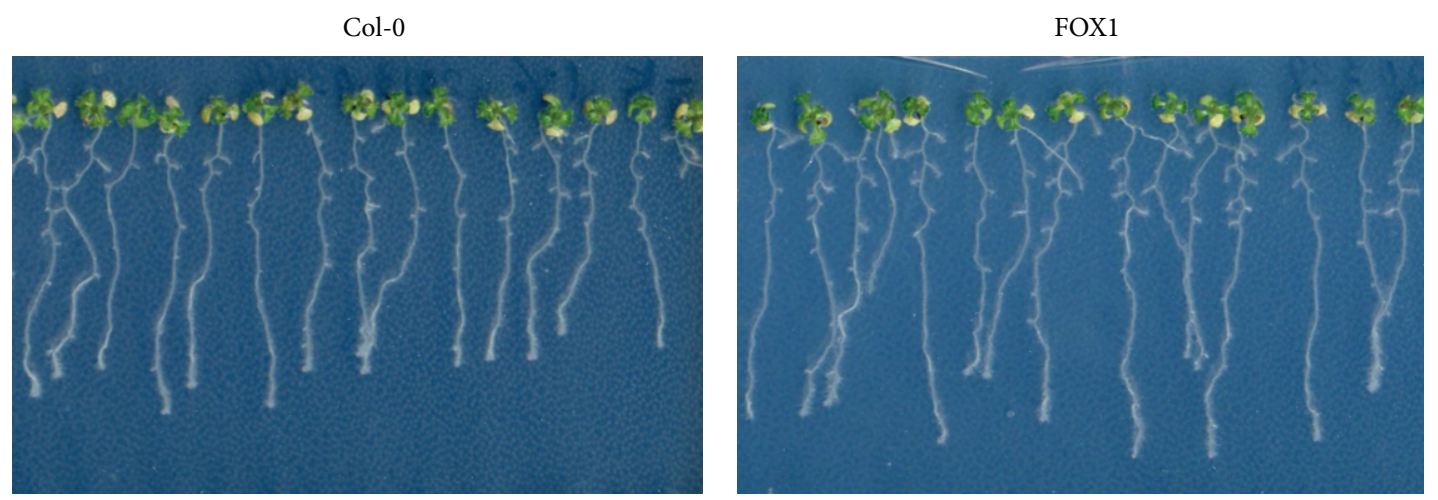

(c)

FIGURE 2: Role of At4g18280 in salt stress and $\mathrm{K}^{+}$-deficiency. (a) Gene expression of HAK5 (crisscross bars) and At4g18280 (white bars) under salt stress. Three-day-old Col-0 seedlings germinated on control media were transferred onto control media or media containing $100 \mathrm{mM}$ $\mathrm{NaCl}$ and grown for 7 days prior to analysis. Values are $\log _{2}$ ratios relative to the control condition. Error bars indicate standard error for three biological replicates with three technical replicates. Each sample contained more than 15 seedlings. Statistically significant differences $(P<0.01)$ compared to each control sample are indicated as asterisks. (b) Primary root lengths of Col-0 (black bars) and FOX1 (dotted bars). Three-day-old seedlings germinated on control media were transferred onto control media or media lacking $\mathrm{K}^{+}(-\mathrm{K})$ and grown for 11 days prior to measurement. Error bars indicate standard error $(n \geq 78)$. Statistically significant differences $(P<0.01)$ compared to Col- 0 are indicated as an asterisk. (c) Image of Col- 0 and FOX1 on $-\mathrm{K}$. Three-day-old seedlings germinated on control media were transferred onto $-\mathrm{K}$ and grown for 11 days prior to imaging.

associated with enhanced primary root growth under the $\mathrm{K}^{+}$deficient condition. Although primary root lengths of FOX1 were comparable to those of Col-0 in the control condition, lateral root number, lateral root density, and root and shoot weight were increased in FOX1 in the control condition, but not to the same extent in the $\mathrm{K}^{+}$-deficient condition. These data indicate that induced HAK5 expression caused by overexpression of At4g18280 or overexpression of At4g18280 alone renders enhanced general growth to the plants. These data also indicate that overexpression of At4g18280 causes less sensitivity to $\mathrm{K}^{+}$-deficiency in terms of primary root growth but not in terms of secondary root growth or shoot growth. This lower sensitivity of FOX1 to $\mathrm{K}^{+}$-deficiency was not due to changes in $\mathrm{K}^{+}$accumulation in the plant body, suggesting that At4g18280 is unlikely to be directly involved in $\mathrm{K}^{+}$uptake.

Transcriptional regulation of the five genes induced in the roots in response to $\mathrm{K}^{+}$-deficiency was also analysed under nitrogen-deficiency, phosphorus-deficiency, and salt stress. Both HAK5 and At4g18280 were shown to be dramatically induced in response to salt stress. This might suggest that At4g18280 was a general transcriptional regulator for HAK5; however, its expression was not induced by cesium treatment ( $\log _{2}$ fold change 0.18 ) which could induce HAK5 expression [10]. $\mathrm{Na}^{+}$concentrations in FOX1 were comparable to those in Col-0 under the control condition, $\mathrm{K}^{+}$-deficiency, or salt 


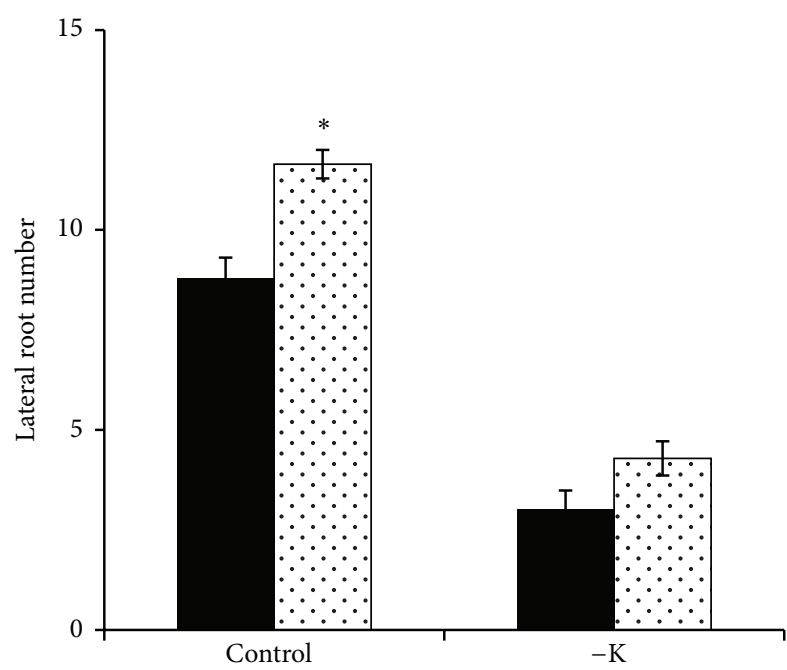

(a)

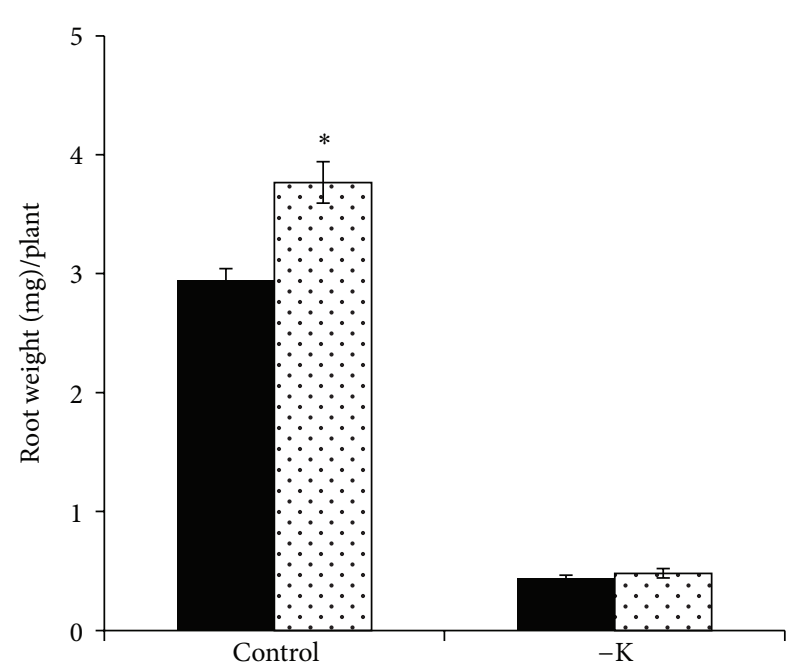

(c)

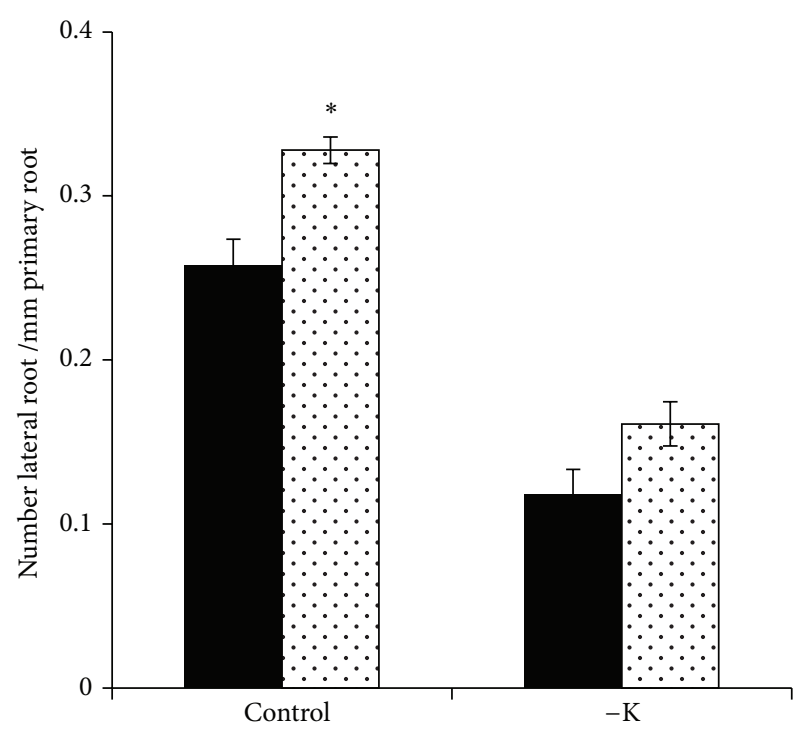

(b)

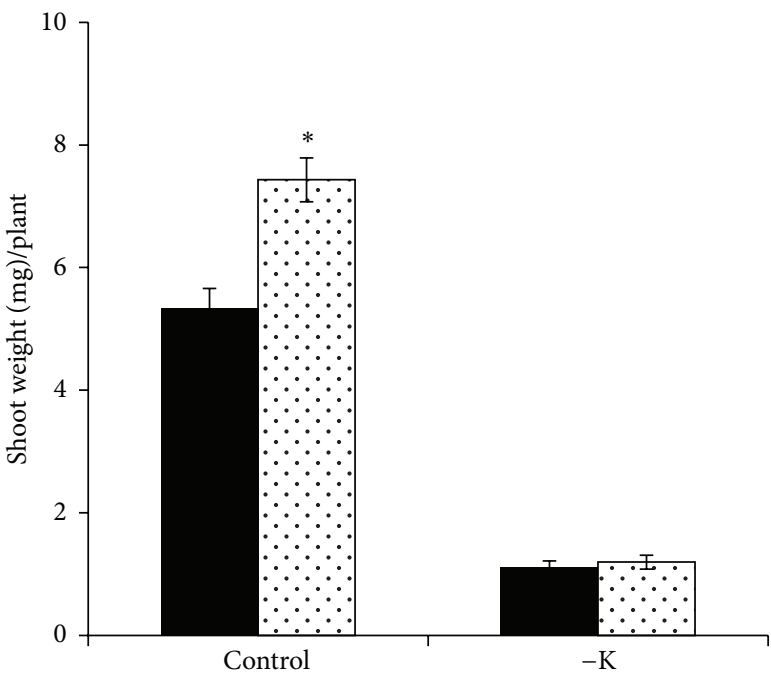

(d)

FIgURE 3: Physiological analysis of FOX1. (a) Lateral root number, (b) lateral root density, (c) fresh root weight, and (d) fresh shoot weight of Col-0 (black bars) and FOX1 (dotted bars). Three-day-old seedlings germinated on control media were transferred onto control media or media lacking $\mathrm{K}^{+}(-\mathrm{K})$ and grown for 11 days prior to measurement. Error bars indicate standard error. $n=14$ for (a) and (b), $n=6$ with each replicate containing 7 seedlings for $(\mathrm{c})$ and (d). Statistically significant differences $(P<0.01)$ compared to Col- 0 are indicated as asterisks.

stress. Also, no morphological phenotype was observed in FOX1 under salt stress. Taken together, At4g18280 is not likely to have a direct role in $\mathrm{Na}^{+}$uptake.

According to the eFP Browser (http://bar.utoronto.ca/ efp/cgi-bin/efpWeb.cgi), it is shown that At4g18280 is predominantly expressed in reproductive organs such as siliques and seeds under normal condition, where HAK5 is also expressed. At4g18280 is annotated as a protein related to glycine-rich cell wall protein according to the TAIR website (http://www.arabidopsis.org/); however, it lacks conventional glycine-rich domains [21]. BLAST (http://blast.ncbi .nlm.nih.gov/) search reveals no known protein with high similarity and a protein domain search engine SMART (http://smart.embl-heidelberg.de/) does not identify any conserved domains or motifs. A gene encoding a glycinerich protein from alfalfa was reported to be induced by salt and drought stresses and abscisic acid treatment [22]. Arabidopsis glycine-rich protein GRP9, whose transcripts are salt-inducible, is suggested to be involved in lignin synthesis in response to salt stress [23]. Although these previous findings correspond conveniently with our data, At4g18280 is unlikely to be a glycine-rich cell wall protein.

\section{Conclusion}

An approach combining promoter reporter constructs and the FOX hunting system successfully revealed a list of genes that might be capable of regulating HAK5 expression. Of 


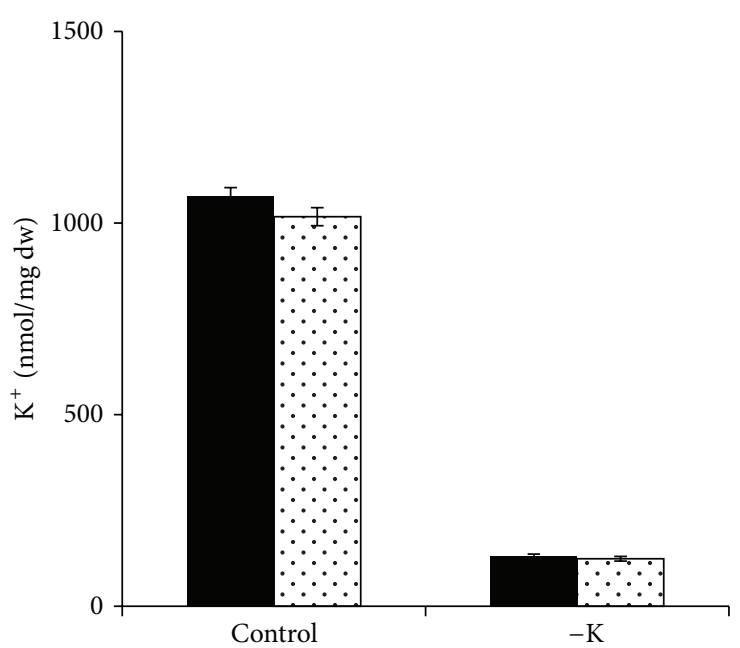

(a)

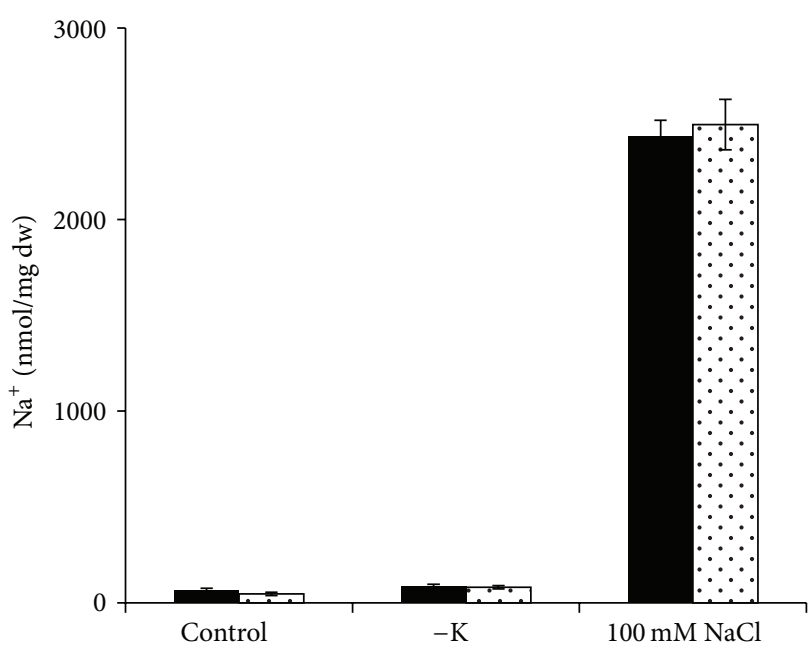

(b)

FIgURE 4: $\mathrm{K}^{+}$and $\mathrm{Na}^{+}$concentrations in FOX1. (a) $\mathrm{K}^{+}$and (b) $\mathrm{Na}^{+}$concentrations in Col-0 (black bars) and FOX1 (dotted bars). Three-dayold seedlings germinated on control media were transferred onto control media, media lacking $\mathrm{K}^{+}(-\mathrm{K})$, or media containing $100 \mathrm{mM} \mathrm{NaCl}$ and grown for 11 days prior to analysis. Error bars indicate standard error for four to six biological replicates. Each replicate contained more than 15 seedlings.

those, we have shown that a novel component At4g18280 is coregulated with $H A K 5$ in $\mathrm{K}^{+}$-deficiency and salt stress response, and overexpression of this gene induces HAK5 expression even under the $\mathrm{K}^{+}$-sufficient conditions in Arabidopsis. This coexpression is likely specific to $\mathrm{K}^{+}$and $\mathrm{Na}^{+}$ responses rather than a general monovalent cation response since expression of At4g18280 is not induced in response to cesium, which induces HAK5 expression. However, $\mathrm{K}^{+}$ and $\mathrm{Na}^{+}$concentrations do not increase in the plants which overexpress At4g18280, suggesting that other components are required to activate $\mathrm{HAK} 5$ for $\mathrm{K}^{+}$, and possibly $\mathrm{Na}^{+}$, uptake. Overexpression of At 4 g18280 enhances general plant growth and provides a mechanism through which plants can adapt to $\mathrm{K}^{+}$-deficiency, possibly due to efficient use of nutrients. Further functional study of At4g18280 is awaited to reveal the entire picture of HAK5 regulation through this novel component.

\section{Conflict of Interests}

The authors declare that there is no conflict of interests regarding the publication of this paper.

\section{Acknowledgments}

This research was financially supported by RIKEN. The authors thank Ms. Takae Miyazaki for taking care of the plants and Dr. Michael Adams for comments and discussion on the paper.

\section{References}

[1] A. Amtmann, J. P. Hammond, P. Armengaud, and P. J. White, "Nutrient sensing and signalling in plants: potassium and phosphorus," Advances in Botanical Research, vol. 43, pp. 209257, 2005.

[2] F. Alemán, M. Nieves-Cordones, V. Martínez, and F. Rubio, "Root $\mathrm{K}^{+}$acquisition in plants: the Arabidopsis thaliana model," Plant and Cell Physiology, vol. 52, no. 9, pp. 1603-1612, 2011.

[3] Y.-F. Tsay, C.-H. Ho, H.-Y. Chen, and S.-H. Lin, "Integration of nitrogen and potassium signaling," Annual Review of Plant Biology, vol. 62, pp. 207-226, 2011.

[4] J. López-Bucio, A. Cruz-Ramírez, and L. Herrera-Estrella, "The role of nutrient availability in regulating root architecture," Current Opinion in Plant Biology, vol. 6, no. 3, pp. 280-287, 2003.

[5] M. Basset, G. Conejero, M. Lepetit, P. Fourcroy, and H. Sentenac, "Organization and expression of the gene coding for the potassium transport system AKT1 of Arabidopsis thaliana," Plant Molecular Biology, vol. 29, no. 5, pp. 947-958, 1995.

[6] Z. Qi, C. R. Hampton, R. Shin, B. J. Barkla, P. J. White, and D. P. Schachtman, "The high affinity $\mathrm{K}^{+}$transporter AtHAK5 plays a physiological role in planta at very low $\mathrm{K}^{+}$concentrations and provides a caesium uptake pathway in Arabidopsis," Journal of Experimental Botany, vol. 59, no. 3, pp. 595-607, 2008.

[7] E. J. Kim, J. M. Kwak, N. Uozumi, and J. I. Schroeder, “AtKUP1: an Arabidopsis gene encoding high-affinity potassium transport activity," The Plant Cell, vol. 10, no. 1, pp. 51-62, 1998.

[8] R. Shin and D. P. Schachtman, "Hydrogen peroxide mediates plant root cell response to nutrient deprivation," Proceedings of the National Academy of Sciences of the United States of America, vol. 101, no. 23, pp. 8827-8832, 2004.

[9] J.-Y. Jung, R. Shin, and D. P. Schachtman, "Ethylene mediates response and tolerance to potassium deprivation in Arabidopsis," The Plant Cell, vol. 21, no. 2, pp. 607-621, 2009.

[10] E. Adams, P. Abdollahi, and R. Shin, "Cesium inhibits plant growth through jasmonate signaling in Arabidopsis thaliana," International Journal of Molecular Sciences, vol. 14, no. 3, pp. 4545-4559, 2013.

[11] M. J. Kim, D. Ruzicka, R. Shin, and D. P. Schachtman, "The Arabidopsis AP2/ERF transcription factor RAP2. 11 modulates 
plant response to low-potassium conditions," Molecular Plant, vol. 5, no. 5, pp. 1042-1057, 2012.

[12] J.-P. Hong, Y. Takeshi, Y. Kondou, D. P. Schachtman, M. Matsui, and R. Shin, "Identification and characterization of transcription factors regulating Arabidopsis HAK5," Plant and Cell Physiology, vol. 54, no. 9, pp. 1478-1490, 2013.

[13] T. Ichikawa, M. Nakazawa, M. Kawashima et al., "The FOX hunting system: an alternative gain-of-function gene hunting technique," The Plant Journal, vol. 48, no. 6, pp. 974-985, 2006.

[14] M. Higuchi, Y. Kondou, T. Ichikawa, and M. Matsui, "Fulllength cDNA overexpressor gene hunting system (FOX hunting system)," Methods in Molecular Biology, vol. 678, pp. 77-89, 2011.

[15] S. J. Ahn, R. Shin, and D. P. Schachtman, "Expression of KT/KUP genes in Arabidopsis and the role of root hairs in $\mathrm{K}^{+}$ uptake," Plant Physiology, vol. 134, no. 3, pp. 1135-1145, 2004.

[16] F. J. M. Maathuis, "The role of monovalent cation transporters in plant responses to salinity," Journal of Experimental Botany, vol. 57, no. 5, pp. 1137-1147, 2006.

[17] H. Su, D. Golldack, C. Zhao, and H. J. Bohnert, “The expression of HAK-type $\mathrm{K}^{+}$transporters is regulated in response to salinity stress in common ice plant," Plant Physiology, vol. 129, no. 4, pp. 1482-1493, 2002.

[18] Q. Leng, R. W. Mercier, B.-G. Hua, H. Fromm, and G. A. Berkowitz, "Electrophysiological analysis of cloned cyclic nucleotide-gated ion channels," Plant Physiology, vol. 128, no. 2, pp. 400-410, 2002.

[19] R. Shin, A. Y. Burch, K. A. Huppert et al., "The Arabidopsis transcription factor MYB77 modulates auxin signal transduction," The Plant Cell, vol. 19, no. 8, pp. 2440-2453, 2007.

[20] C. R. Hampton, H. C. Bowen, M. R. Broadley et al., "Cesium toxicity in Arabidopsis," Plant physiology, vol. 136, no. 3, pp. 3824-3837, 2004.

[21] A. Mangeon, R. M. Junqueira, and G. Sachetto-Martins, "Functional diversity of the plant glycine-rich proteins superfamily," Plant Signaling \& Behavior, vol. 5, no. 2, pp. 99-104, 2010.

[22] R. Long, Q. Yang, J. Kang et al., "Overexpression of a novel salt stress-induced glycine-rich protein gene from alfalfa causes salt and ABA sensitivity in Arabidopsis," Plant Cell Reports, vol. 32, no. 8, pp. 1289-1298, 2013.

[23] A.-P. Chen, N.-Q. Zhong, Z.-L. Qu, F. Wang, N. Liu, and G.-X. Xia, "Root and vascular tissue-specific expression of glycine-rich protein AtGRP9 and its interaction with AtCAD5, a cinnamyl alcohol dehydrogenase, in Arabidopsis thaliana," Journal of Plant Research, vol. 120, no. 2, pp. 337-343, 2007. 

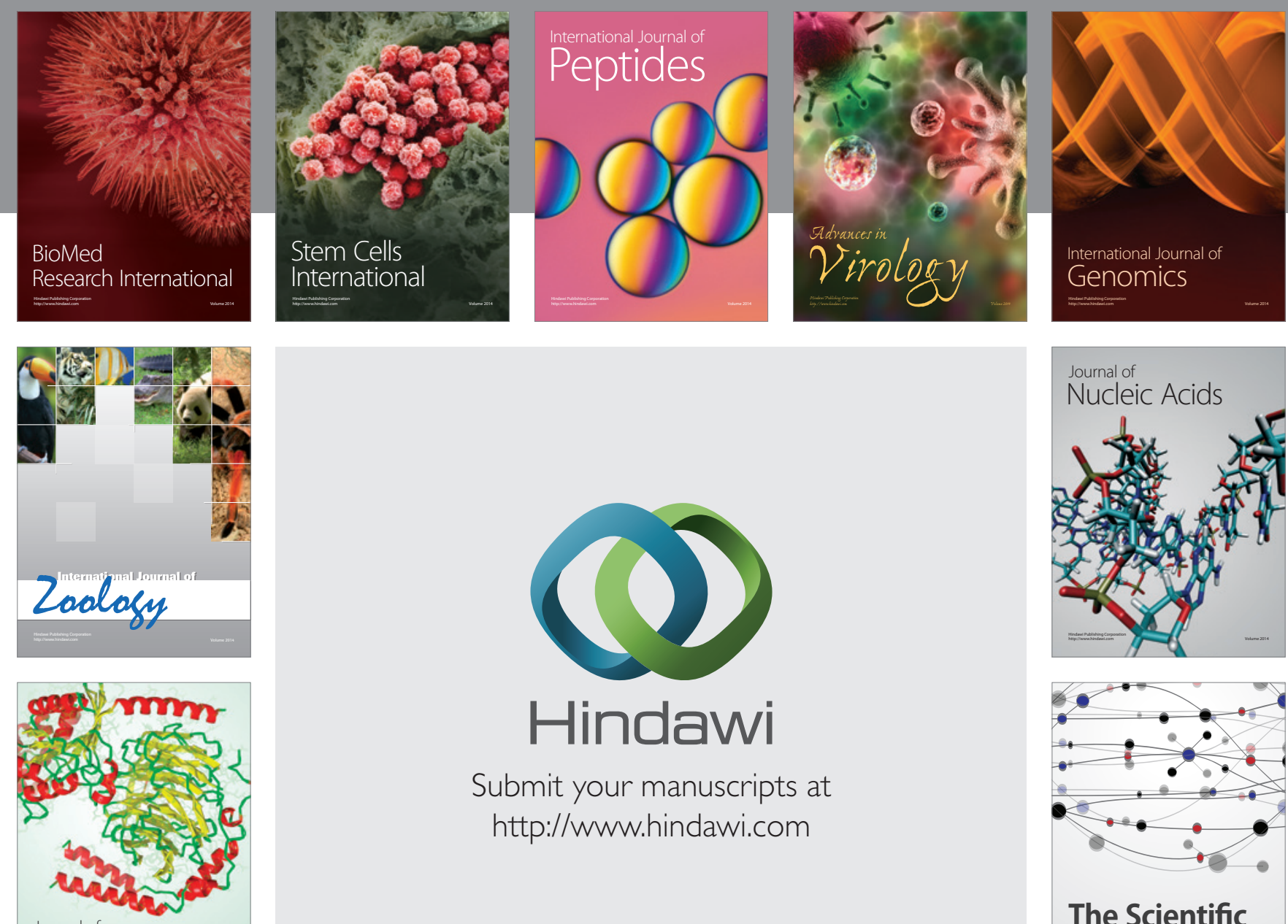

Submit your manuscripts at

http://www.hindawi.com

Journal of
Signal Transduction
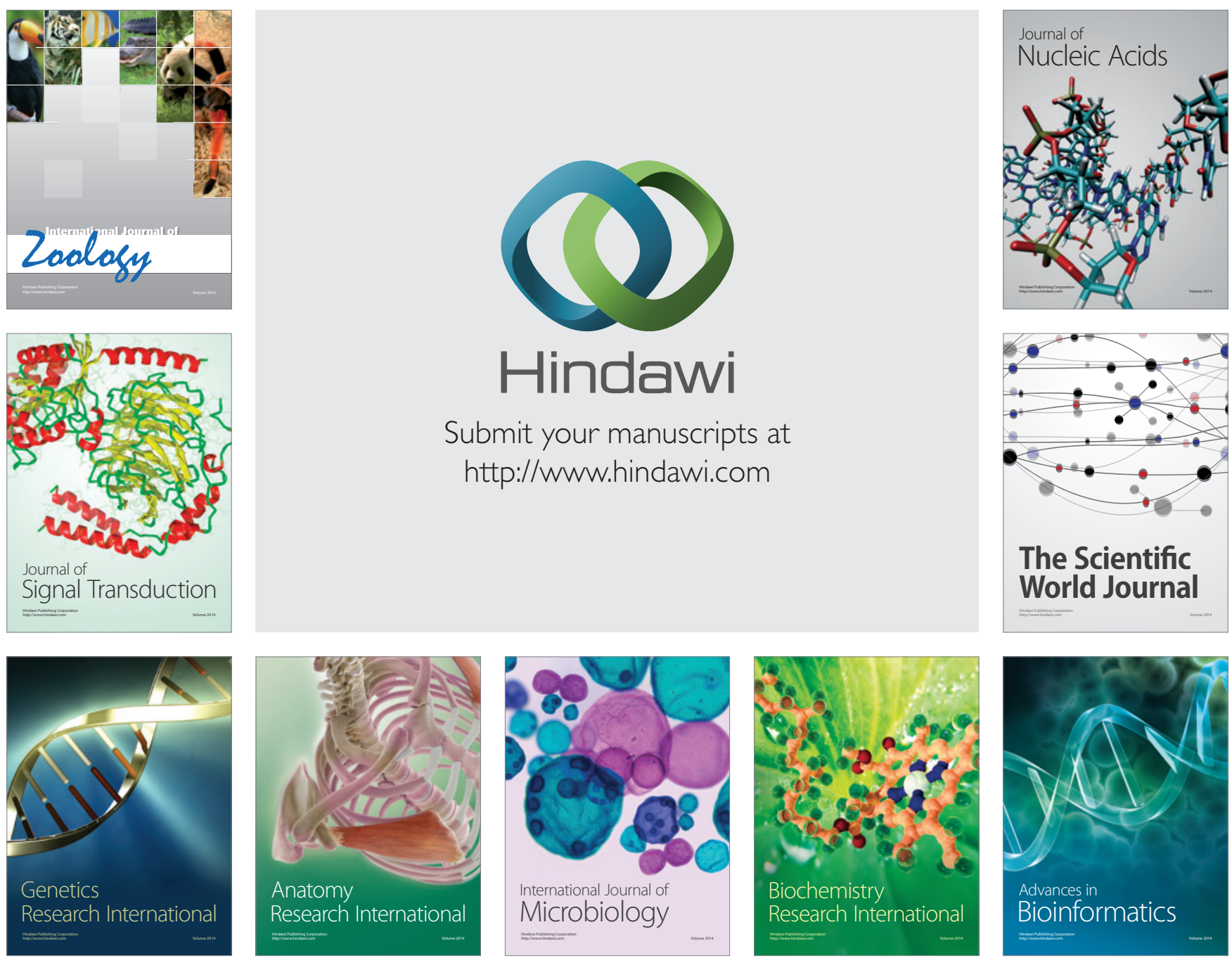

The Scientific World Journal
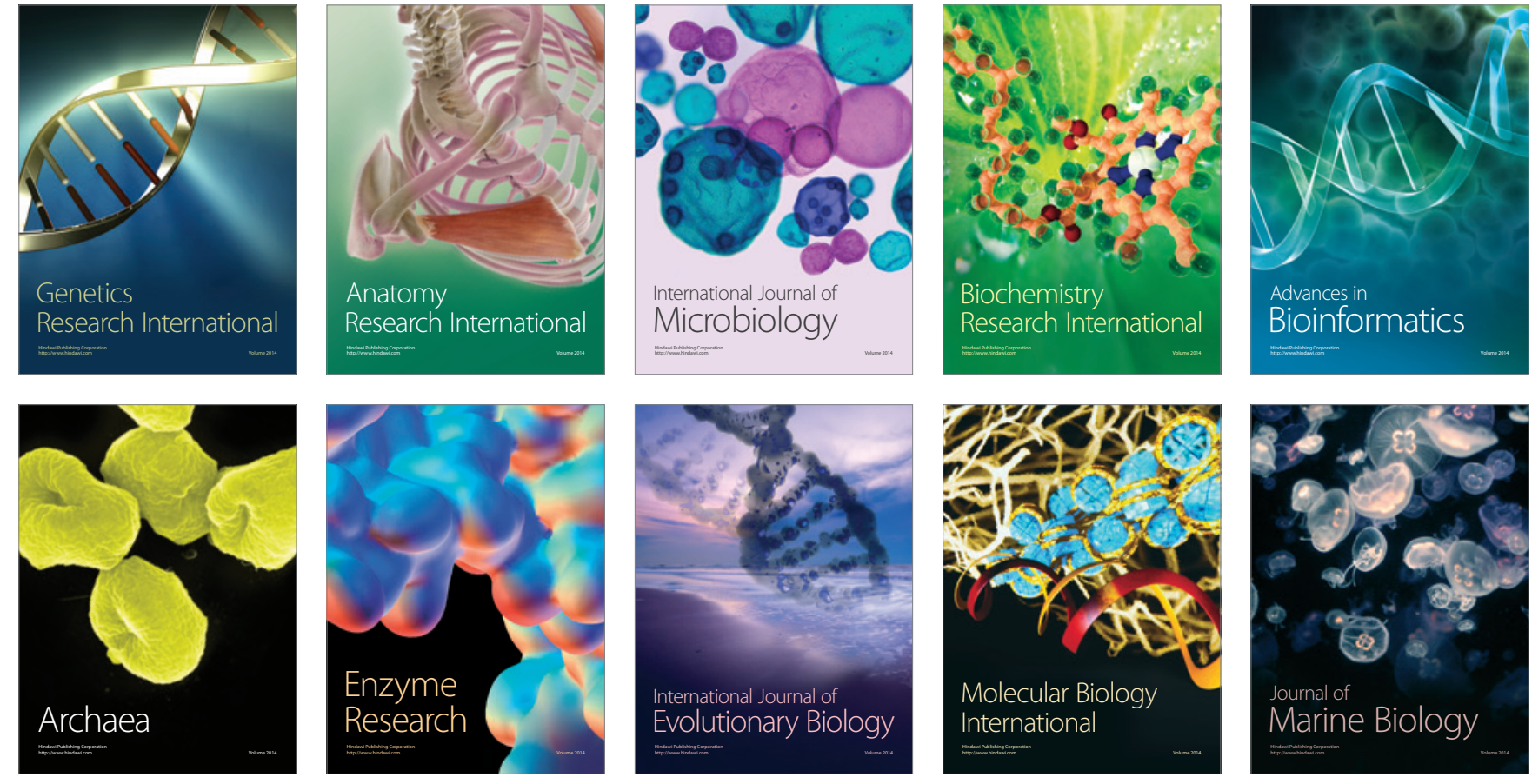